\title{
microRNA-145 suppresses lung adenocarcinoma-initiating cell proliferation by targeting OCT4
}

\author{
RONG YIN $^{1 *}$, SHUAI ZHANG $^{1 *}$, YAQIN WU $^{1}$, XIAOHU FAN ${ }^{2}$, FENG JIANG $^{1}$, \\ ZHI ZHANG ${ }^{1}$, DONGJIE FENG ${ }^{1}$, XIRONG GUO ${ }^{3}$ and LIN XU ${ }^{1}$

\begin{abstract}
${ }^{1}$ Department of Thoracic Surgery, Nanjing Medical University Affiliated Cancer Hospital of Jiangsu Province, Edmonton T6E2E1, Canada; ${ }^{3}$ Institute of Pediatrics, Nanjing Medical University, 210029 Nanjing, P.R. China
\end{abstract} \\ Cancer Institution of Jiangsu Province, Nanjing 210009, P.R. China; ${ }^{2}$ Department of Pediatrics, University of Alberta,
}

Received January 20, 2011; Accepted March 14, 2011

DOI: $10.3892 /$ or.2011.1252

\begin{abstract}
Recent studies demonstrated that microRNA-145 is downregulated in human cancer cells and may function as a tumor suppressor. However, its role in lung cancer tumorigenesis remains unclear. Here, we demonstrated that upregulation of miR-145 reduced the proliferation and invasion as well as the ratio of CD133-positive initiating cells and the tumorosphere growth capacity of the human lung adenocarcinoma A549 cell line. The direct targeting of miR-145 to OCT4 mRNA was predicted by bioinformatic analysis and validated by a luciferase reporter system. We, therefore, confirmed that miR-145 can impair the proliferation of human lung adenocarcinoma-initiating cells by targeting OCT4 and leads to inhibition of lung cancer development.
\end{abstract}

\section{Introduction}

Non-small cell lung cancer (NSCLC) is one of the leading causes of cancer-related deaths in industrialized countries (1). Despite improvements in early diagnosis made possible by emerging technologies and newly developed chemo-targeted therapies that improve treatment responses, the overall 5-year survival rate for NSCLC patients remains $<20 \%$ (2). It is still necessary to further elucidate the mechanisms involved in the tumorigenesis of NSCLC and discover novel therapeutic targets (3).

microRNAs (miRNAs) are a group of endogenous and non-coding small single strain RNAs (only 19-22 nucleotides),

Correspondence to: Dr Lin Xu, Department of Thoracic Surgery, Nanjing Medical University Affiliated Cancer Hospital of Jiangsu Province, Cancer Institution of Jiangsu Province, 42 Baiziting, Nanjing 210009, P.R. China

E-mail: xulin_83@yahoo.cn

Dr Xirong Guo, Institute of Pediatrics, Nanjing Medical University, 210029 Nanjing, P.R. China

E-mail:xrguo@njmu.edu.cn

*Contributed equally

Key words: microRNA, cancer initiating cells, proliferation which can bind with the 3'-untranslated region (3'-UTRs) of messenger RNAs of target genes and cleave them posttranscriptively (4). In cancer research, many miRNAs are also considered as potential oncogenes or tumor-suppressor genes (5). Increasing bioinformatics evidence and subsequent functional assays of miRNAs have indicated that some special miRNAs are involved in many steps during cancer progression, such as apoptosis, proliferation, differentiation, migration and metastasis (5). Notably, recent studies have indicated that they emerged as key regulators of stemness, collaborating in the maintenance of pluripotency, control of self-renewal, and differentiation of cancer stem cells (CSCs) (6,7). For example, overexpression of let-7 can inhibit breast cancer initiating cell (CIC) proliferation, mammosphere formation in vitro and CIC-inducing metastasis in NOD/SCID mice in vivo (8). miR-34 may suppress the self-renew ability of pancreatic CSCs by targeting Bcl-2 and Notch which control the transdifferentiation and survival of CSCs (9).

Recent studies of microRNA signature have indicated that miR-145 was significantly downregulated in lung cancer (10), breast cancer (11) and colon caner (12). In early 2010, Sachdeva et al demonstrated that miR-145-mediated suppression of a breast cancer cell line is in part due to the silencing of the metastasis gene mucin-1 (13). However, the role of miR-145 in the tumorigenesis of NSCLC remains unclear. In the present study, we confirmed that miR-145 is downregulated in clinical tumor tissues of lung adenocarcinoma (LAC). Overexpression of miR-145 reduced the proliferation and invasion ability of human LAC cell line A549. Interestingly, the ratio of CD133-positive CICs was decreased and the tumorsphere growth capacity was suppressed. The direct targeting of miR-145 to the OCT4 mRNA was predicted by bioinformatics analysis and validated by luciferase reporter gene assay. We therefore concluded that miR-145 can impair human LAC initiating cell proliferation via targeting OCT4 and then leads to inhibition of lung cancer development.

\section{Materials and methods}

Ethics statement of clinical samples. All clinical samples were obtained from patients who signed informed consent 
approving the use of their tissues for research purposes post surgery. The use of human tissues in this study was approved by the Institutional Review Board of Jiangsu Province Cancer Hospital and was in accordance with their guidelines.

Cell culture and tissue collection. Human LAC cell line A549, human bronchioloalveolar epithelial cell line BEAS2B and human embryonic kidney (HEK) 293T cells were obtained from American Type Culture Collection (ATCC, USA). A549 and BEAS2B cells were cultured in RPMI-1640 (HyClone) supplemented with $10 \%$ fetal bovine serum (FBS, Invitrogen). HEK-293T cells were cultured in DMEM (HyClone) supplemented with $10 \%$ FBS. Cultures were maintained under an atmosphere containing 5\% $\mathrm{CO}_{2}$ (Forma Scientific). Twenty freshly resected lung-cancer specimens and their adjacent normal lung tissues were collected from the Department of Thoracic Surgery in Cancer Hospital of Jiangsu Province. The specimens were snap-frozen in liquid nitrogen.

Identification of microRNA target. The miRanda algorithm http://www.microrna.org/microrna/getMrna.do?gene= uc003nsu.1 \&organism=9606\# was used to identify human microRNA binding sites in OCT4 (gene ID 5460). Briefly, miRanda provides 3'UTR alignments with predicted sites and links to various public databases for prediction of microRNA binding sites.

Luciferase assay. Luciferase reporter gene assay was performed to investigate whether Oct4 expression was regulated by miR-145. The luciferase-UTR reporter constructs were generated by, respectively, introducing the wild-type OCT4 3'-UTR carrying a putative miR-145 binding site and mutated OCT4 3'-UTR without the putative binding site into psiCHECK-2 control vector (Promega). The 3'-UTR of wild-type Oct4 was amplified by PCR using primers OCT4-UTR-XhoI-5.1: 5'-gect cgagGGTGCCTGCCCTTCTAGGAATG-3' and OCT4-UTRNotI-3.1: 5'-cagcggccgcTAAGTGTGTCTATCTACTGTG-3'. In order to induce a mutation of the putative miR-145 binding site of OCT4 3'-UTR, we used QuikChange Site-Directed Mutagenesis Kit (Stratagene). Mutated OCT4 3'-UTR was amplified by using primers OCT4-UTR-5.2: 5'-GGGAGTTT GGGGCTTGACCTTGGAGGGAAGGTGA-3' and OCT4UTR-3.2: 5'-TCACCTTCCCTCCAAGGTCAAGCCCCAA ACTCCCCT-3'. The psiCHECK-2 control vector expressing renilla luciferase (Promega) was used for normalization of cell number and transfection efficiency. Co-transfection of synthetic miR-145 mimics and mimics control, or miR-145 inhibitor and inhibitor control were also performed in HEK 293T cells by using Lipofectamine ${ }^{\mathrm{TM}} 2000$ Transfection Reagent (Invitrogen). Renilla luciferase activity was determined by Promega Dual Luciferase Assay System (Promega) according to the manufacturer's protocol.

Cell transfection. A549 cells were transfected at $60 \%$ confluence and overexpression of miR-145 was achieved by transfection with a miR-145 duplex that mimics the mature miR-145 (Ambion). Transfection with the miR-145 mimics negative control (Ambion) was used as control. miR-145 inhibitor (Ambion) was transfected to downregulate the expression of miR-145 in cells while the miR-145 inhibitor negative control
(Ambion) was used as control. Cells added transfection reagents only were used as blank. All transfections were carried out using Lipofectamine 2000 Transfection Reagent (Invitrogen) according to the manufacturer's protocol. Cells were transfected with $20 \mathrm{nM}$ of oligonucleotides. The transfection efficiency of miR-145 mimics and inhibitor was evaluated by transfection with the FAM-labelled fluorescent negative controls (Ambion), respectively.

Total RNA extraction and real-time PCR. For miR-145, total RNA was extracted using mirVana RNA Isolation Kit (Applied Biosystems). Mature miR-145 levels were quantified using TaqMan microRNA Assay (Applied Biosystems). Quantification was normalized to the U6 small nuclear B non-coding RNA (RNU6B, Applied Biosystems) which served as an endogenous control. For Oct4, total RNA was also extracted using mirVana RNA Isolation Kit and real-time RT-PCR was performed using SYBR Premix Ex Taq kit (Takara). PCR primers for Oct4 were: 5'-ACATCAAAGCTCTGCAGAAAGAAC-3' (forward) and 5'-CTGAATACCTTCCCAAATAGAACCC-3' (reverse). The expression levels of Oct4 were normalized to $\beta$-actin. All protocols were carried out according to manufacturer's protocols. Real-time PCR was performed by using 7500 real-time PCR system (Applied Biosystems). Each sample was run in triplicate. Ct-value for each sample was calculated with the $\Delta \Delta \mathrm{Ct}$-method and results were expressed as $2^{-\Delta \Delta \mathrm{CT}}$ as previously described (14).

Western blotting and reagents. Blank and oligonucleotidetransfected cells were seeded onto a 6-well plate at density of $10^{6}$ cells per well. Proteins were extracted $48 \mathrm{~h}$ after plating by lysing the cells in each well in $300 \mu$ l of lysis buffer containing protease inhibitors (150 mM NaCl, $25 \mathrm{mM}$ Tris- $\mathrm{HCl}, \mathrm{pH} 8.0$, 0.5 M EDTA, 20\% Triton X-100, 8 M Urea, and $1 \mathrm{X}$ protease inhibitor cocktail). After the addition of lysis buffer, cells were scraped off and kept on ice for $30 \mathrm{~min}$. Protein concentration of lysates was measured by BCA protein assay kit (Pierce) after centrifugation at $14000 \mathrm{rpm}$ for $5 \mathrm{~min}$. Lysates with $60 \mu \mathrm{g}$ of protein were subjected to SDS-PAGE for Oct4 detection. The separated proteins were transferred to PVDF membranes followed by immunostaining with Oct4 antibody (Abcam) overnight at $4^{\circ} \mathrm{C}$ at a dilution of 1:1000. After washing, the membrane was incubated with goat anti-rabbit HRP-conjugated secondary antibody (Abcam) at a dilution of 1:10000 for $2 \mathrm{~h}$ at room temperature followed by ECL detection. After detection of protein bands, the blot was reprobed with the primary antibody against $\beta$-actin to confirm equal loading samples. The $\beta$-actin antibody (Abcam) was incubated overnight at $4^{\circ} \mathrm{C}$ at a dilution of 1:5000. The secondary antibody was used as previously described, followed by washes, detection with the ECL kit (Thermo Scientific) and autoradiography.

Cell proliferation assay. Cells were transfected with miR-145 duplex, negative control or blank transfected as described above. Cells were plated on 96-well plates at 4000 cells in $100 \mu 1$ per well and detected in quadruplicate at various time points for 5 days. To the detected cells, $10 \mu \mathrm{l}$ of Cell Counting Kit-8 (Dojindo) was added into each well and viable cells were measured by absorbance at $450 \mathrm{~nm}$ after incubation at 
$37^{\circ} \mathrm{C}$ for $3 \mathrm{~h}$. Absorbance values were normalized to media control.

Tumor invasion assay. Pre-chilled serum-free RPMI-1640 was mixed with matrigel (1:5; BD). The upper hanging millicell chambers (Millipore) were filled with $100 \mu \mathrm{l}$ of the mixture inserted into 24-well plates (Corning), and the matrigel was allowed to solidify at $37^{\circ} \mathrm{C}$ for $4 \mathrm{~h}$. After solidification, 50,000 cells were trypsinized, washed, resuspended in RPMI-1640 contained $0.01 \%$ FBS (Gibco), and placed evenly in the upper chambers. The lower chambers contained 5\% FBS (Gibco) in RPMI-1640 was used as a chemoattractant. After incubation at $37^{\circ} \mathrm{C}$ in $5 \% \mathrm{CO}_{2}$ for $24 \mathrm{~h}$, non-invaded cells in the upper chambers were removed with a cotton swab, and invaded cells were washed with PBS twice and fixed in $70 \%$ methanol. Fixed cells were stained with $0.1 \%$ crystal violet for $10 \mathrm{~min}$ and imaged. Four random fields were analyzed for each chamber. Assays were conducted in triplicate in three independent experiments.

Cell cycle analysis and CD133 staining. For cell cycle analysis by flow cytometry, A549 cells were transfected with oligonucleotides in 6-well plates, trypsinized $72 \mathrm{~h}$ later and washed with PBS, and fixed in $70 \%$ ethanol at $4^{\circ} \mathrm{C}$ overnight. After centrifugation, cells were stained with $50 \mu \mathrm{g} / \mathrm{ml}$ propidium iodide (BD) and $0.1 \mu \mathrm{g} / \mathrm{ml}$ RNase A, and analyzed using a FACSCalibur flow cytometer. Each histogram was constructed with the data from at least 10,000 events. Cells were harvested by $10 \mathrm{mM}$ EDTA in PBS and adjusted to a concentration of $2 \times 10^{6}$ cells $/ \mathrm{ml}$. For CD133 staining, cells were incubated in PBS containing $3 \% \mathrm{BSA}$ in the presence of $10 \mu \mathrm{g} / \mathrm{ml}$ FITCconjugated antihuman CD133 (eBioscience) antibody for $1 \mathrm{~h}$ in the dark. Samples were also analyzed by FACSCalibur. Data were analyzed to calculate the $\%$ of cell population in each phase using FlowJo 7.6 software.

Tumorosphere culture. The tumorspheres culture was similar to that previously described (14). Briefly, A549 cells were cultured in serum-free DMEM-F12 medium (Sigma) containing $100 \mu \mathrm{g}$ / $\mathrm{ml}$ insulin (Sigma), 0.6\% glucose, $5 \mathrm{mM}$ HEPES, 0.4\% BSA, and $1 \%$ antibiotics, and supplemented with $20 \mathrm{ng} / \mathrm{ml} \mathrm{EGF}$ (BD) and $20 \mathrm{ng} / \mathrm{ml} \mathrm{bFGF} \mathrm{(BD).} \mathrm{Cells} \mathrm{were} \mathrm{seeded} \mathrm{at} \mathrm{a} \mathrm{clonal}$ density (3000 cells per well) in the ultra low adherent 24-well plates (Corning). The medium was replaced or supplemented with fresh growth factors twice a week until cells started to grow forming floating aggregates. About 10-14 days later, tumorspheres were observed and quantified under an inverted microscope (Leica). Subsequently, in order to quantify cell numbers per tumorsphere, they were disassociated enzymatically (10 min in $0.05 \%$ trypsin, $0.53 \mathrm{mM}$ EDTA-4Na; Invitrogen) and collected with a $40-\mu \mathrm{m}$ sieve (BD) to make a single cell suspension. Then the viable cells were counted by trypan blue staining.

Statistical analysis. Data are given as the mean \pm SD. Data were analyzed using a commercially available statistical software package (SPSS for Windows, version 13.0, Chicago, IL). Student's t-test and one-way ANOVA was used to analyze all the results statistically. $\mathrm{p}<0.05$ was considered statistically significant.
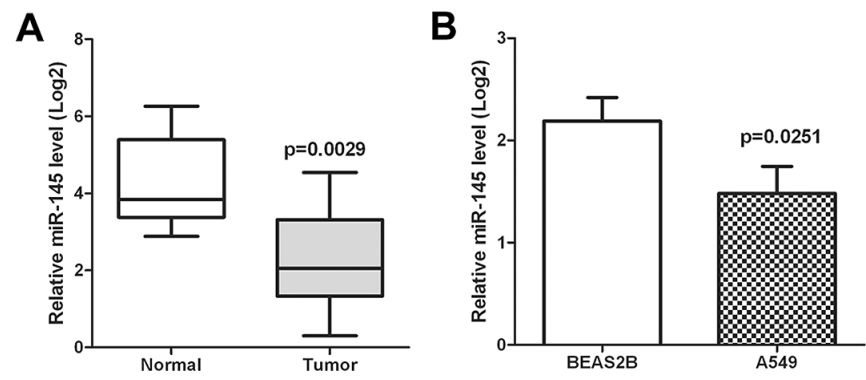

Figure 1. Relative miR-145 expression level determined by real-time RT-PCR (the values are standardized by $\log 2$ ). (A) miR-145 expression level of clinical lung adenocarcinoma (LAC) samples and adjuvant normal lung tissues. (B) miR-145 expression level of human LAC cell line A549 and bronchioloalveolar epithelial cell line BEAS2B.

\section{Results}

miR-145 was downregulated in both clinical LAC tissues and A549 cell line. Real-time RT-PCR revealed that the expression levels of miR-145 were significantly decreased $>5$ fold in clinical LAC samples as compared with the adjacent normal samples (Fig. 1A, p=0.0029). Similarly, miR-145 expression level of A549 cells was also $40 \%$ lower than normal bronchioloalveolar epithelial BEAS2B cells (Fig. 1B, p=0.0251).

Transfection efficiency evaluation of the miR-145 mimics and inhibitor. At $5 \mathrm{~h}$ after transfection, fluorescent microscopy showed emissive green fluorescence (Fig. 2A). We further confirmed that the transfection efficiency of miR-145 mimics and inhibitor was $>80 \%$ by using flow cytometry (Fig. 2B). As shown in Fig. 2C, in the miR-145 mimics group, the expression level of miR-145 was $\sim 14$-fold higher than blank ( $\mathrm{p}<0.001)$. A six-fold decreased expression of miR-145 was also observed in miR-145 inhibitor group compared to blank $(\mathrm{p}<0.001)$. There were no significant differences among the miR-145 mimics negative control, inhibitor negative control, and blank groups (Fig. 2C).

miR-145 modulates the proliferation and cell invasion of A549 cells. The proliferation rate of A549 cells with enhanced or silenced miR-145 expression was determined via CCK-8 assay. Compared to blank and negative control cells, cells transfected with miR-145 mimics proliferated at a significantly lower rate. In contrast, silenced expression of miR-145 resulted in significant proliferation (Fig. 3). We also evaluated the role of miR-145 on cell invasion by Transwell assay. As compared with blank and negative control cells, the invasion potential of A549 cells transfected with the miR-145 mimics was significantly decreased while cells transfected with miR-145 inhibitor displayed markedly increased invasive ability (Fig. 4).

miR-145 modulates $S$ phase population of A549 cells. As shown in Fig. 5, cell cycle distribution by flow cytometry showed that $\mathrm{S}$ phase population was inhibited in the cells transfected with the miR-145 mimics while an increase of $S$ phase population was observed in the miR-145 inhibitor group as compared with blank and negative controls. 
A
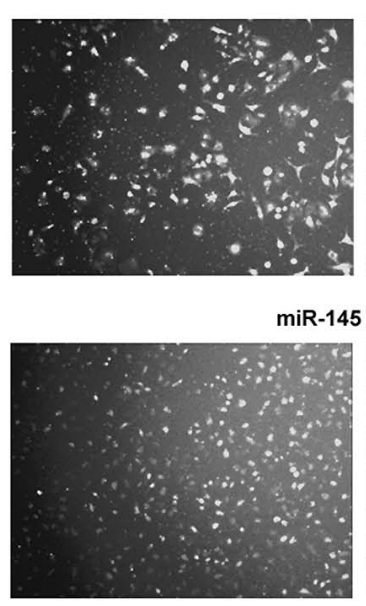

Fluorescence
miR-145 mimics

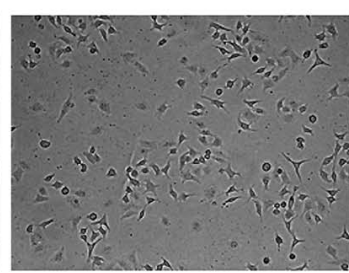

\section{inhibitor}

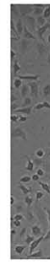

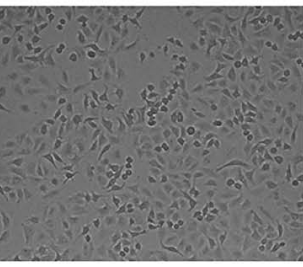

Light
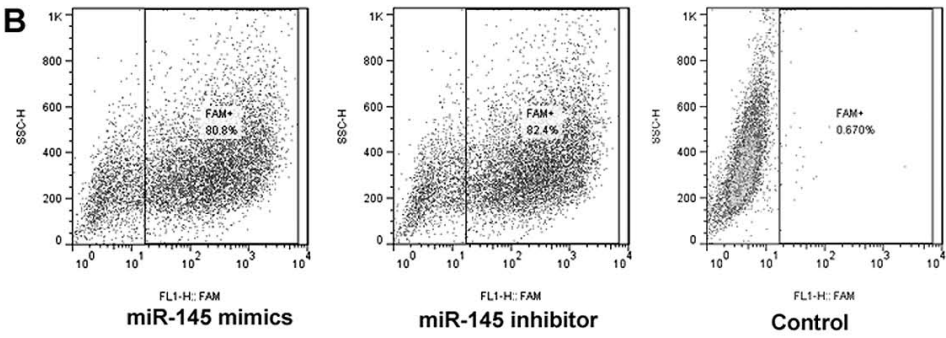

C

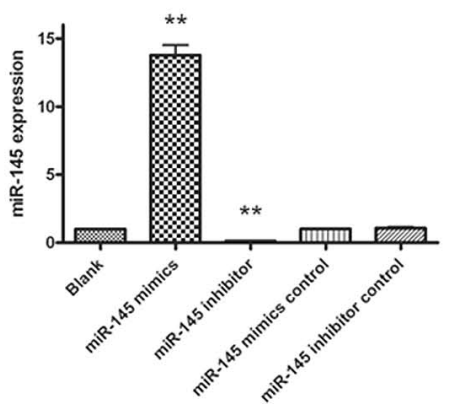

Figure 2. Transfection efficiency evaluation of the miR-145 mimics and inhibitor. (A) Representative figures of A549 cells transfected by miR-145 mimics and inhibitors under fluorescent and light scope, respectively. (B) Green fluorescence-positive cell ratio in the miR-145 mimics, inhibitor and control groups. (C) miR-145 expression level determined by real-time RT-PCR in miR-145 mimics, inhibitor and control groups. $\left.{ }^{* *} \mathrm{p}<0.001\right)$.

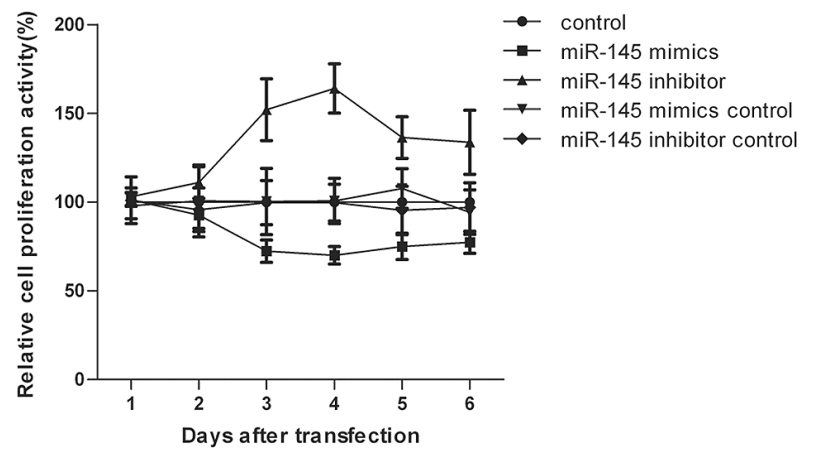

Figure 3. Proliferation rate of A549 cells determined by CCK-8 assay.
miR-145 directly targets 3'UTR of OCT4. Using bioinformatics analysis, such as miRanda and TargetScan, we found that miR-145 contained specific binding sequences for the 3'UTR region of the OCT4 gene (Fig. 6A). In agreement with the computer prediction, OCT4 protein levels were significantly suppressed in the miR-145 mimics group whereas increased in miR-145 inhibitor group (Fig. 6B). In order to further validate the relationship between miR-145 and OCT4, dual luciferase reporter assay were performed in HEK293T cells. The sequences of 3'UTR of wild-type and mutated OCT4 are shown in Fig. 6C. No reduction of luciferase activity was observed in HEK293T cells transfected with miR-145 mimics
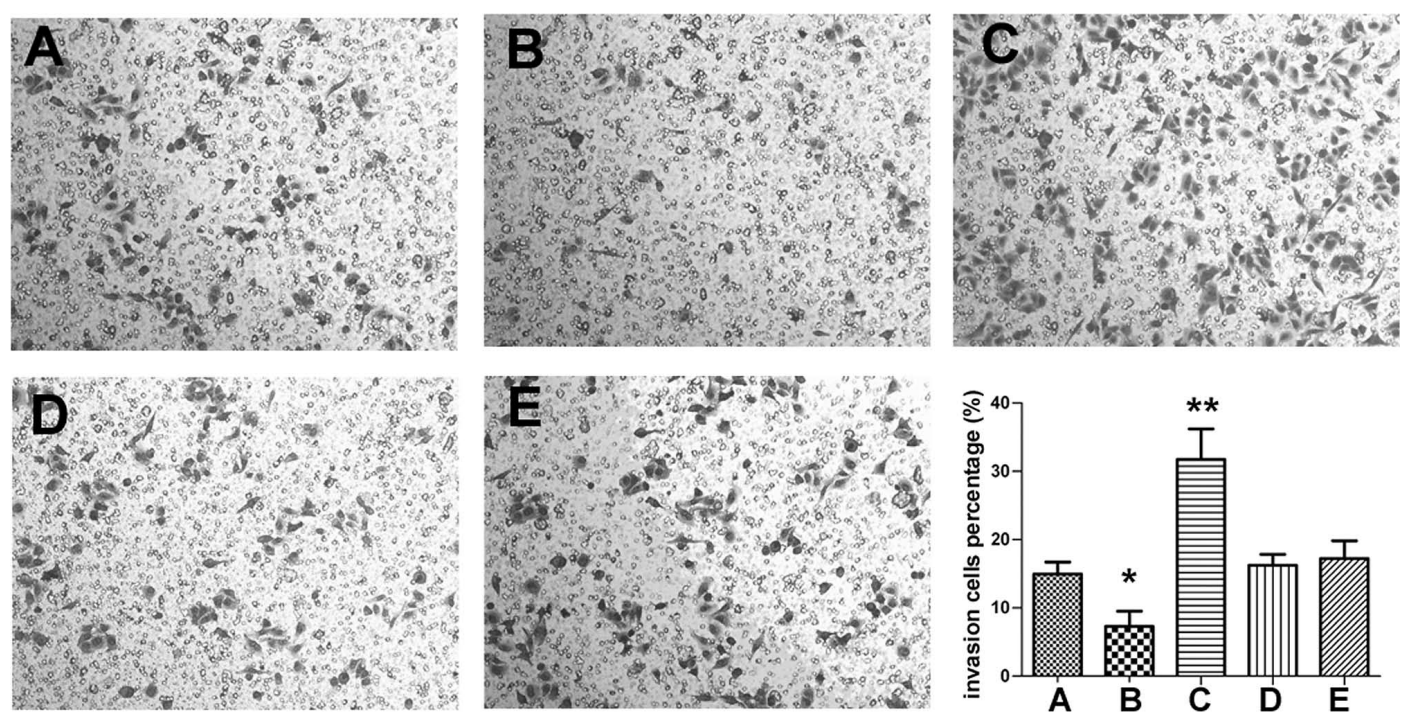

Figure 4. Cell invasion capacity evaluation of A549 cells by Transwell assay. (A) Blank; (B) miR-145 mimics; (C) miR-145 inhibitor; (D) miR-145 mimics control; (E) miR-145 inhibitor control. ( $\left.{ }^{*} \mathrm{p}<0.01 ;{ }^{* *} \mathrm{p}<0.001\right)$. 

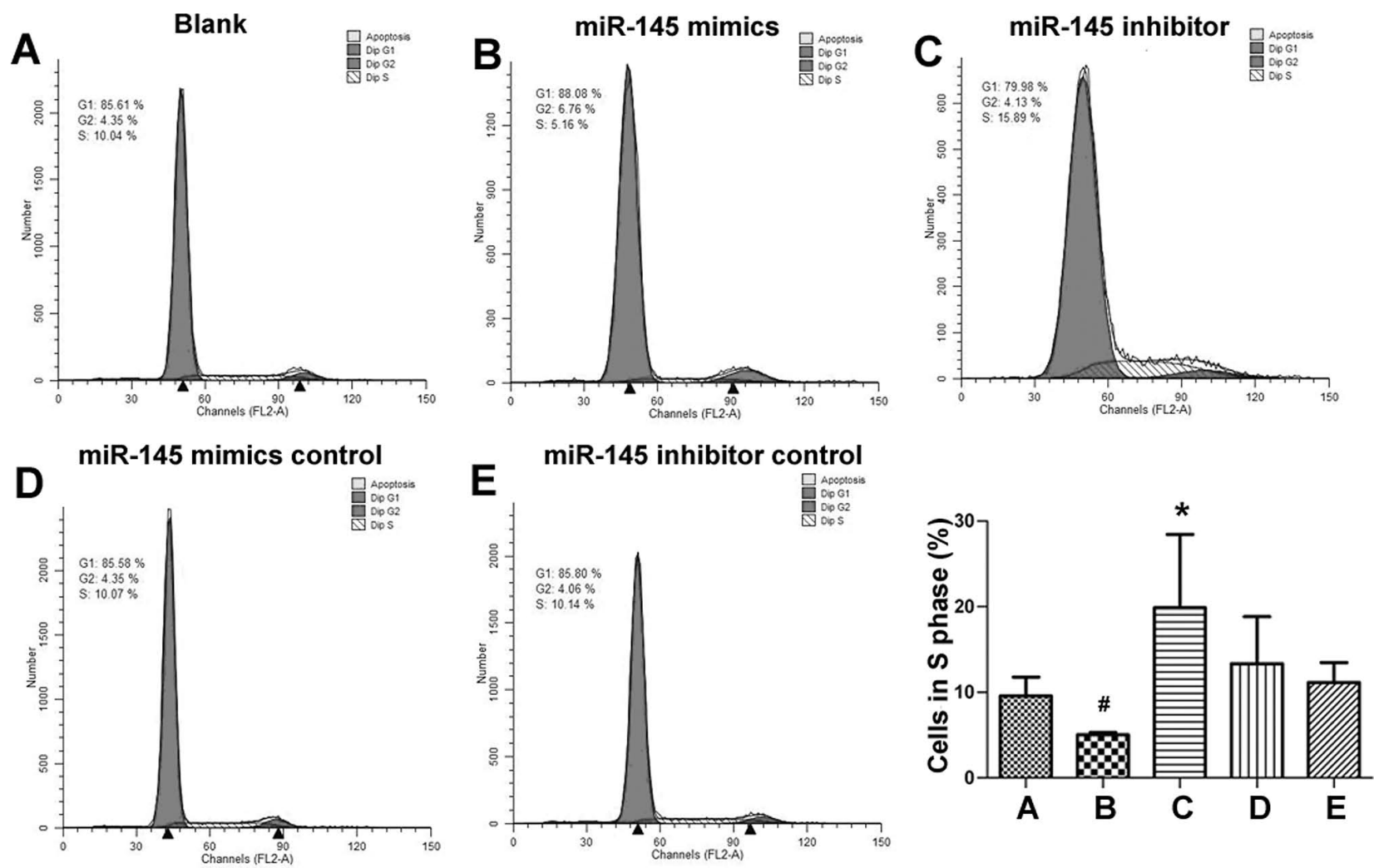

Figure 5. Cell cycle analysis of A549 cells by flow cytometry propidium iodide staining. (A) Blank; (B) miR-145 mimics; (C) miR-145 inhibitor; (D) miR-145 mimics control; (E) miR-145 inhibitor control. ("p $<0.01$; $\left.{ }^{* *} \mathrm{p}<0.001\right)$.

A

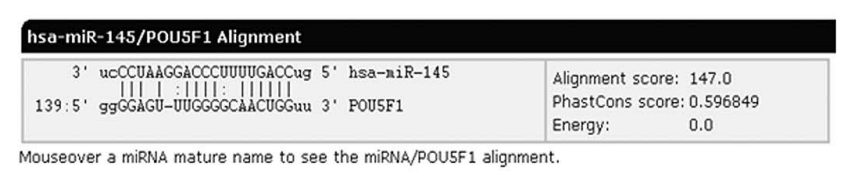

Bioinformatics prediction by miRanda

$\operatorname{miR}-145$

C

$$
\begin{aligned}
& \text { 3' UCCCUAAGGACCCUUUUGACCUG 5' } \\
& \text { 5' ...AGGGGAGT - TTGGGGCAACTGGTT...3' } \\
& \text { WT-OCT4 } \\
& \text { 5' ...AGGGGAGT - TTGGGGCTTGACCTT...3' } \\
& \text { Mut-OCT4 }
\end{aligned}
$$

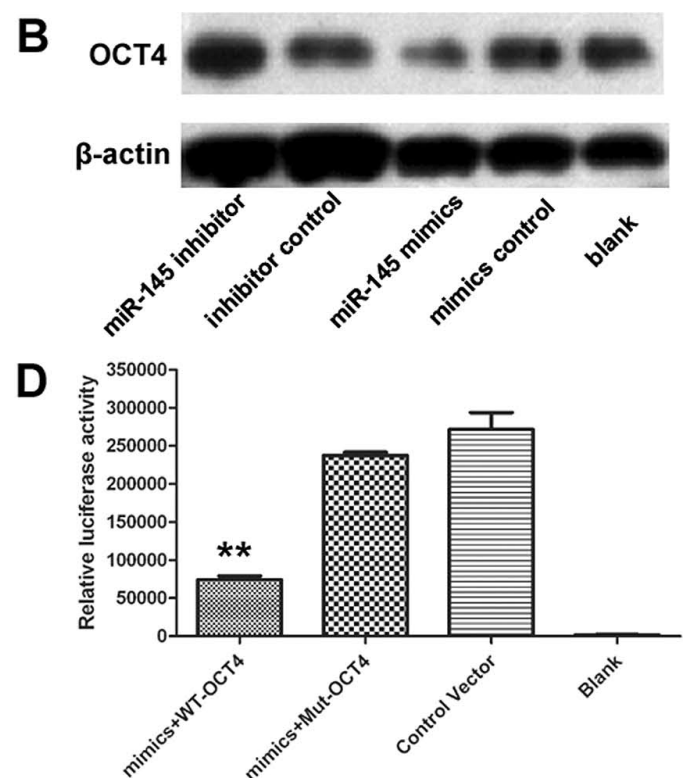

Figure 6. miR-145 directly targets OCT4 mRNA. (A) Bioinformatics prediction by miRanda. (B) OCT4 protein level determined by Western blotting in A549 cells transfected by miR-145 mimics, inhibitor and control groups. (C) Top, alignment of OCT4 3'-UTR and miR-145; Bottom, mutant OCT4 3'UTR structure without the putative binding site. (D) Luciferase reporter gene assay in HEK-293T cells transfected by miR-145 mimics + wild-type OCT4-3'UTR, miR-145 mimics + mutant OCT4-3'UTR and empty control vectors.

and mutated OCT4, but $>60 \%$ reduction of luciferase activity was observed in wild-type OCT4 (p<0.001, Fig. 6D).

Overexpression of miR-145 leads to a significant reduction of $\mathrm{CD} 133^{+}$cell ratio and tumorsphere growth of A549 cells.
To investigate the potential effect of miR-145 on the tumor initiating cells (TICs) of A549, we first examined the CD133 surface marker of cells. We found that the ratio of CD133 population was decreased distinctly in the cells $72 \mathrm{~h}$ after transfected with miR-145 mimics and increased greatly in 

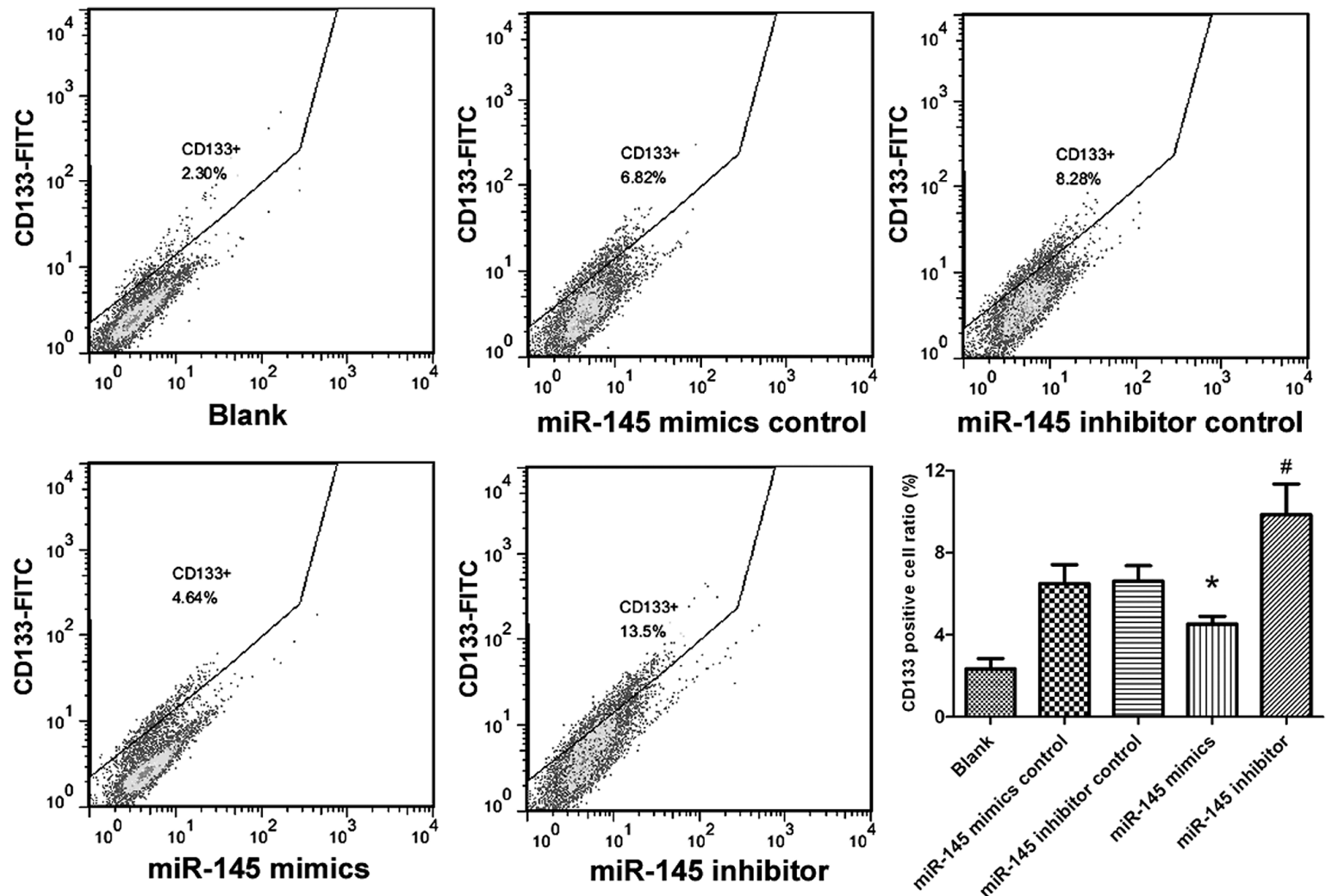

Figure 7. CD133-positive cell ratio analysis of A549 cells determined by CD133-FITC staining in the miR-145 mimics, inhibitor and control groups. ("p<0.01; $\left.{ }^{\#} \mathrm{p}<0.05\right)$.

A

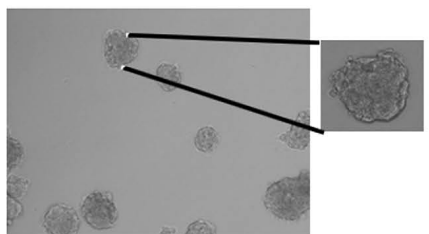

miR-145 inhibitor

B

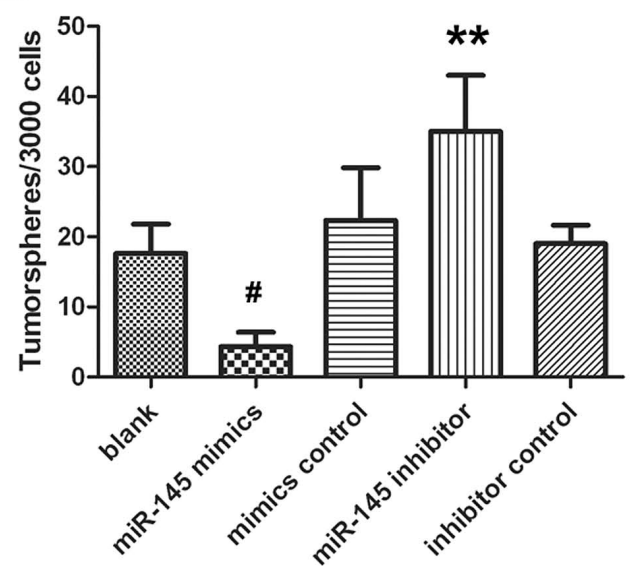

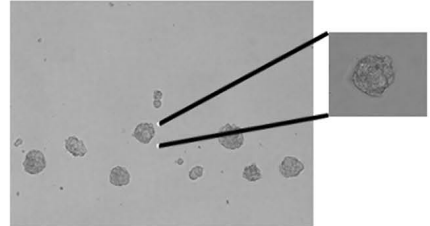

miR-145 mimics

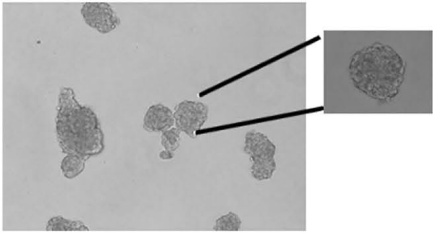

blank

C

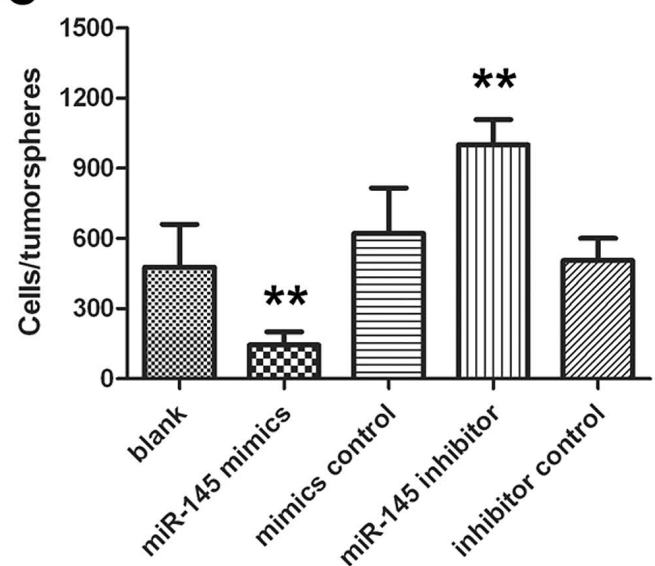

Figure 8. Tumorsphere culture and proliferation assay of A549 tumor initiating cells. (A) Representative figures of tumorsphere growth in miR-145 mimics, inhibitor and control groups. (B) Tumorsphere numbers counting per 3000 cells. (C) Cell numbers counting per tumorsphere. $\left({ }^{*} \mathrm{p}<0.05{ }^{*} \mathrm{p}<0.01 ;{ }^{* *} \mathrm{p}<0.001\right)$.

the cells transfected with miR-145 inhibitor in contrast with negative controls (Fig. 7). The effect of miR-145 on TIC proliferation was further determined by tumorsphere culture. Fig. 8 shows that both the numbers of tumorspheres $/ 3000$ 
cells and cell numbers per tumorsphere were significantly decreased in the miR-145 mimics group and increased in the miR-145 inhibitor group.

\section{Discussion}

Recent studies have indicated that miR-145 is a potential tumor suppressor in numerous cancers. However, the role of miR-145 in tumorigenesis of NSCLC remains unclear. In the present study, we demonstrated that miR-145-mediated lung adenocarcinoma inhibition was at least in part due to the suppression of TIC proliferation by targeting OCT4 in human A549 cell lines. Our data also highlight the significance of miR-145 as a potential repressive target for treating lung cancer.

Previous studies have demonstrated that the expression of miR-145 is abnormally decreased in human NSCLC (15). In agreement with the findings of Cho et al (16), we confirmed that miR-145 expression was significantly downregulated in the clinical LAC samples and A549 cell line. However, Cho et al only indicated that restoration of miR-145 can inhibit cell proliferation of EGFR-mutant LAC cell lines. Our results fully demonstrate that overexpression of miR-145 can induce cell arrest, as well as inhibition of cell proliferation and invasion in LAC cell line A549.

It has been observed that a single microRNA might bind to as many as 200 gene targets and that these targets can be diverse in their function (17). The known target genes of miR-145 identified by previous cancer studies include PPP3CA, CBFB, YES, STAT1, and MUC1 $(13,18,19)$. By using Bioinformatics software prediction, we found that OCT4 is also a potential target gene of miR-145, which was supported by the data that miR-145 can directly bind the 3'UTR sites of OCT4 by luciferase reporter gene assay in the present study.

OCT4 belongs to the family of POU-domain transcription factors involved in the regulation of cell growth and differentiation. OCT4, as well as SOX2 and KLF4 are considered as three typical transcription factors of embryonic stem (ES) cells. They control the self-renewing capacity and pluripotency in both mouse and human ES cells $(20,21)$. These three transcription factors are also considered as the most necessary genes in induced pluripotent stem cell (iPS) technology. In addition, strong expression of OCT4 is also observed in various human cancers, such as brain, breast, lung, renal, colon cancer (22). It is recently reported that OCT4 could also be used clinically as a diagnostic tool in primary and metastatic embryonic carcinomas (23). Recent evidence shows that overexpression of OCT4 results in rapid expansion of progenitor cells and invasive tumor formation indicating that OCT4 can also act as a powerful oncogene in lung adenocarcinoma (24). Therefore, OCT 4 could also be used as a lung cancer stem cell marker (25). Our data indicated that miR-145 regulates the expression of OCT4 which may be one of the modulators of the cell growth and invasion.

Another important aspect of the present study is that our results are the first to link miR-145 with the lung cancer stem cells or tumor initiating cells. Recent data have demonstrated that tumors contain a small subpopulation of cells called cancer stem cells (CSCs) which exhibit a self-renewing capacity and are responsible for tumor maintenance and metastasis (26). CD133 has been considered an important marker to represent the subset population of CSCs in prostate cancer, pancreatic cancers, colon carcinoma and lung cancers (14,27-29). By flow cytometry, we showed that miR-145 regulates the CD133 positive subpopulation in the lung cancer cells. Chen et al revealed that OCT4 expression maintained cancer stem-like properties in lung cancer-derived CD133-positive cells (26). We propose that miR-145 may regulate the CD133-positive subset at least in part by targeting OCT4. Xu et al reported that miR-145 and OCT4 form a double-negative feedback loop that switches the human embryonic cells between self-renewal and differentiation and consequently reduced the proliferation of human ES cells (30). Whether there is a similar negative interaction between miR-145 and OCT4 in lung cancer and other cancers is still unclear.

In summary, miR-145 is a multi-functional potential tumor suppressor that regulates a variety of biological processes. Our data indicated the miR-145 may inhibit the proliferation and invasion capacity of LAC cells. Our study provides the first evidence that miR-145 is involved in TIC proliferation and tumorspheres growth by directly targeting OCT- 4 which is essential to the pluripotency and self-renewing capacity of CSCs. Therefore, via regulating TICs, the restoration of tumor suppressor miR-145 may provide a novel therapeutic approach for lung adenocarcinoma.

\section{Acknowledgements}

The present work was supported by the Leading Medical Investigator Grant of Jiangsu Province (LJ200625) and Science Foundation of Jiangsu Province (BK2010589) for Dr Lin $\mathrm{Xu}$. The authors thank Dr Genbao Feng for his technical assistance.

\section{References}

1. Spira A and Ettinger DS: Multidisciplinary management of lung cancer. N Engl J Med 350: 379-392, 2004.

2. Vora N and Reckamp KL: Non-small cell lung cancer in the elderly: defining treatment options. Semin Oncol 35: 590-596, 2008.

3. Lam WK and Watkins DN: Lung cancer: future directions. Respirology 12: 471-477, 2007.

4. Lim LP, Lau NC, Garrett-Engele P, Grimson A, Schelter JM, Castle J, Bartel DP, Linsley PS and Johnson JM: Microarray analysis shows that some microRNAs downregulate large numbers of target mRNAs. Nature 433: 769-773, 2005.

5. Iorio MV and Croce CM: microRNAs in cancer: small molecules with a huge impact. J Clin Oncol 27: 5848-56, 2009.

6. Hatfield S and Ruohola-Baker H: microRNA and stem cell function. Cell Tissue Res 331: 57-66, 2008.

7. Navarro A and Monzo M: microRNAs in human embryonic and cancer stem cells. Yonsei Med J 5: 622-632, 2010.

8. Yu F, Yao H, Zhu P, Zhang X, Pan Q, Gong C, Huang Y, Hu X, Su F, Lieberman J and Song E: let-7 regulates self renewal and tumorigenicity of breast cancer cells. Cell 131: 1109-1123, 2007.

9. Ji Q, Hao X, Zhang M, Tang W, Yang M, Li L, Xiang D, Desano JT, Bommer GT, Fan D, Fearon ER, Lawrence TS and Xu L: microRNA miR-34 inhibits human pancreatic cancer tumor-initiating cells. PLoS One 4: e6816, 2009.

10. Yanaihara N, Caplen N, Bowman E, Seike M, Kumamoto K, Yi M, Stephens RM, Okamoto A, Yokota J, Tanaka T, Calin GA, Liu CG, Croce CM and Harris CC: Unique microRNA molecular profiles in lung cancer diagnosis and prognosis. Cancer Cell 9: 189-198, 2006.

11. Sempere LF, Christensen M, Silahtaroglu A, Bak M, Heath CV, Schwartz G, Wells W, Kauppinen S and Cole CN: Altered microRNA expression confined to specific epithelial cell subpopulations in breast cancer. Cancer Res 67: 11612-11620, 2007. 
12. Schepeler T, Reinert JT, Ostenfeld MS, Christensen LL, Silahtaroglu AN, Dyrskjot L, Wiuf C, Sorensen FJ, Kruhoffer M, Laurberg S, Kauppinen S, Orntoft TF and Andersen CL: Diagnostic and prognostic microRNAs in stage II colon cancer. Cancer Res 68: 6416-6424, 2008.

13. Sachdeva M and Mo YY: microRNA-145 suppresses cell invasion and metastasis by directly targeting mucin 1 . Cancer Res 70: 378-387, 2010.

14. Eramo A, Lotti F, Sette G, Pilozzi E, Biffoni M, Di Virgilio A, Conticello C, Ruco L, Peschle C and De Maria R: Identification and expansion of the tumorigenic lung cancer stem cell population. Cell Death Differ 15: 504-514, 2008.

15. Liu X, Sempere LF, Galimberti F, Freemantle SJ, Black C, Dragnev KH, Ma Y, Fiering S, Memoli V, Li H, DiRenzo J, Korc M, Cole CN, Bak M, Kauppinen S and Dmitrovsky E: Uncovering growth-suppressive microRNAs in lung cancer. Clin Cancer Res 15: 1177-1183, 2009.

16. Cho WC, Chow AS and Au JS: Restoration of tumour suppressor hsa-miR-145 inhibits cancer cell growth in lung adenocarcinoma patients with epidermal growth factor receptor mutation. Eur J Cancer 45: 2197-2206, 2009.

17. Esquela-Kerscher A and Slack FJ: Oncomirs - microRNAs with a role in cancer. Nat Rev Cancer 6: 259-269, 2006

18. Ostenfeld MS, Bramsen JB, Lamy P, Villadsen SB, Fristrup N, Sorensen KD, Ulhoi B, Borre M, Kjems J, Dyrskjot L and Orntoft TF: miR-145 induces caspase-dependent and -independent cell death in urothelial cancer cell lines with targeting of an expression signature present in Ta bladder tumors. Oncogene 29: 1073-1084, 2010.

19. Gregersen LH, Jacobsen AB, Frankel LB, Wen J, Krogh A and Lund AH: microRNA-145 targets YES and STAT1 in colon cancer cells. PLoS One 5: e8836, 2010.

20. Takahashi K, Tanabe K, Ohnuki M, Narita M, Ichisaka T, Tomoda $\mathrm{K}$ and Yamanaka S: Induction of pluripotent stem cells from adult human fibroblasts by defined factors. Cell 131: 861-872, 2007
21. Takahashi K and Yamanaka S: Induction of pluripotent stem cells from mouse embryonic and adult fibroblast cultures by defined factors. Cell 126: 663-676, 2006.

22. Schoenhals M, Kassambara A, De Vos J, Hose D, Moreaux J and Klein B: Embryonic stem cell markers expression in cancers. Biochem Biophys Res Commun 383: 157-162, 2009.

23. Sung MT, Jones TD, Beck SD, Foster RS and Cheng L: OCT4 is superior to CD30 in the diagnosis of metastatic embryonal carcinomas after chemotherapy. Hum Pathol 37: 662-667, 2006.

24. Karoubi G, Cortes-Dericks L, Gugger M, Galetta D, Spaggiari L and Schmid RA: Atypical expression and distribution of embryonic stem cell marker, OCT4, in human lung adenocarcinoma. J Surg Oncol 102: 689-98, 2010.

25. Pine SR, Marshall B and Varticovski L: Lung cancer stem cells. Dis Markers 24: 257-266, 2008.

26. Chen YC, Hsu HS, Chen YW, Tsai TH, How CK, Wang CY, Hung SC, Chang YL, Tsai ML, Lee YY, Ku HH and Chiou SH: Oct-4 expression maintained cancer stem-like properties in lung cancer-derived CD133-positive cells. PLoS One 3: e2637, 2008.

27. Collins AT, Berry PA, Hyde C, Stower MJ and Maitland NJ: Prospective identification of tumorigenic prostate cancer stem cells. Cancer Res 65: 10946-10951, 2005.

28. O'Brien CA, Pollett A, Gallinger S and Dick JE: A human colon cancer cell capable of initiating tumour growth in immunodeficient mice. Nature 445: 106-110, 2007.

29. Braine J and Herpin F: Molecular hydrogen beyond the optical edge of an isolated spiral galaxy. Nature 432: 369-371, 2004.

30. Xu N, Papagiannakopoulos T, Pan G, Thomson JA and Kosik KS: microRNA-145 regulates OCT4, SOX2, and KLF4 and represses pluripotency in human embryonic stem cells. Cell 137: 647-658, 2009. 